\title{
MISTURA DE HERBICIDAS COM INSETICIDAS E SEUS EFEITOS SOBRE HÍBRIDOS \\ DE MILHO
}

\author{
MIXTURE OF HERBICIDS WITH INSECTICIDES AND ITS EFFECT ON CORN \\ HYBRIDS
}

\author{
Marluce Gonçalves CORTEZ'; Fábio SALOMONS²; Fabrício Caputo CASTRO²; \\ Silvana OHSE ${ }^{1}$
}

1- Professoras do Departamento de Fitotecnia e Fitossanidade, Curso de Agronomia - Universidade Estadual de Ponta Grossa, Ponta Grossa/PR

2- Acadêmicos do curso de Agronomia da Universidade Estadual de Ponta Grossa, Departamento de Fitotecnia e Fitossanidade, Ponta Grossa-PR.

Autor para correspondência: mgcortez@uepg.br

\section{RESUMO:}

Com o objetivo de avaliar se inseticidas aplicados simultaneamente com herbicidas afetam o desenvolvimento e a produtividade de híbridos de milho (Zea mays L.), foi conduzido um experimento a campo, na Fazenda Escola da UEPG, Ponta Grossa/PR. O experimento foi delineado em blocos casualizados com 4 repetições, contendo os seguintes tratamentos: três níveis do fator herbicida \{mesotrione (120 $\left.\mathrm{g} \mathrm{ha}^{-1}\right)$; atrazine $\left(1250 \mathrm{~g} \mathrm{ha}^{-1}\right)$ e mesotrione + atrazine $\left(120 \mathrm{~g} \mathrm{ha}^{-1}+1250\right.$ $\left.\mathrm{g} \mathrm{ha}^{-1}\right)$; dois híbridos (30P70 e 30K75, ambos da Pioneer), dois inseticidas \{lufenuron (15 g ha-1) e metomyl $\left.\left(129 \mathrm{~g} \mathrm{ha}^{-1}\right)\right\}$, constituindo um fatorial $3 \times 2 \times 2$. Foram avaliadas altura de plantas, número de folhas por planta e diâmetro de colmo aos 0; 16; 32 e 40 DAA, teor de clorofila aos 0 e 24 DAA, fitotoxicidade, fitomassa fresca e seca das plantas daninhas, comprimento e diâmetro de espiga, número de fileiras por espiga, número de grãos por fileira, fitomassa de 1000 grãos e produtividade. A altura de plantas (40 DAA) foi influenciada simultaneamente pelos herbicidas e pelos híbridos. $O$ híbrido 30P70 apresentou maior altura de planta, de inserção da primeira espiga, número de espigas por planta e grãos por fileira. Nas condições em que o ensaio foi realizado, não houve interações entre os tratamentos herbicidas, inseticidas e híbridos de milho em relação à aplicação dos herbicidas para os componentes da produtividade.

Palavras-chave: Zea mays L., mesotrione, atrazine, lufenuron e metomyl.

\section{ABSTRACT:}

With the objective to evaluate if insecticidal applied simultaneously with herbicides they affect the development and the productivity of maize hybrids (Zea mays L.), was lead an experiment the field, in the Farm School of the UEPG, Ponta Grossa/PR. The experiment was delineated block-type randomized with 4 repetitions, contends the following treatments: three levels of the herbicide factor \{mesotrione (120 g.ha-1); atrazine (1250 g ha-1) and mesotrione + atrazine (120 g ha-1 $+1250 \mathrm{~g} \mathrm{ha}^{-}$ $\left.{ }^{1}\right)$ \}; two hybrids (30P70 and 30K75, both of the Pioneer), two insecticides \{lufenuron (15 $\mathrm{g} \mathrm{ha}^{-1}$ ) and metomyl (129 $\left.\mathrm{g} \mathrm{ha}^{-1}\right)$, constituting a factorial $3 \times 2 \times 2$. Height of plants, leaf number for plant and diameter of stem to the had been evaluated $0 ; 16$; 32 e 40 DAA, content of chlorophyll to the 0 and 24 DAA, fitotoxicidade, fitomassa cool and dries of the harmful plants, length and diameter of spike, number of rows for spike, number of grains for row, fitomassa of 1000 grains and productivity. The height of plants (40 DAA) was influenced simultaneously by the herbicides and the hybrids. The hybrid 30P70 presented greater height of plant, of insertion of the first spike, number of spikes for plant and grains for row. In the conditions where the assay was carried through, it did not have interactions between the herbicides, insecticidal and hybrid treatments of maize in relation to the application of the herbicides for the components of the productivity.

Keywords: Zea mays L., mesotrione, atrazine, lufenuron e metomyl. 


\section{INTRODUÇÃO}

A cultura do milho (Zea mays L.) desempenha papel fundamental no sistema de produção brasileiro e mundial. O elevado potencial produtivo, composição química e valor nutritivo, fazem com que esse cereal seja considerado um dos mais importantes, sendo consumido e cultivado mundialmente (Fancelli e Dourado-Neto, 2000). O milho é uma das principais culturas agrícolas cultivadas no Brasil, não somente pelo aspecto quantitativo, mas também por sua importância estratégica, visto que é a base da alimentação animal e, consequentemente, humana.

Apesar de o Brasil ser o terceiro maior produtor mundial de milho, a produtividade média, está em torno de $5.556,0 \mathrm{~kg} \mathrm{ha}^{-1}$ (CONAB, 2017), a qual é considerada baixa comparada à de outros países como a dos EUA (10.719 $\left.\mathrm{kg} \mathrm{ha}^{-1}\right)$ e da Argentina $\left(7.000 \mathrm{~kg} \mathrm{ha}^{-1}\right)$ e pelo potencial produtivo da cultura que é superior a $16.000 \mathrm{~kg} \mathrm{ha}^{-1}$ (Coelho et al., 2003).

O milho é cultivado em praticamente todo o território brasileiro, sendo que $90 \%$ da produção concentraram-se nas regiões Sul, Sudeste e Centro-Oeste. Apesar das flutuações de sua oferta, há uma tendência de crescimento de sua produção, acompanhando, principalmente, o crescimento da produção de frangos e suínos no país, fato esse relacionado com a demanda por milho, que é um ingrediente importante na composição das rações para esses animais (CONAB, 2017).

O milho é uma planta de ciclo vegetativo variado, evidenciando desde cultivares extremamente precoces, cuja polinização pode ocorrer 30 dias após a emergência, até mesmo aqueles cujo ciclo vital pode alcançar 300 dias. Contudo, nas condições brasileiras, a cultura do milho apresenta ciclo variável entre 110 e 180 dias, em função da caracterização dos cultivares (superprecoce, precoce e normal), período este compreendido entre a semeadura e a colheita (Fancelli e Dourado 2000).

Entre os fatores bióticos que reduzem o rendimento das culturas encontram-se as plantas daninhas, as quais podem afetar negativamente a produção econômica (Taiz et al., 2017). O milho é uma cultura bastante sensível a mato competição. De maneira geral, as plantas daninhas interferem no desenvolvimento das plantas de milho com intensidade variável, em função da época de ocorrência, da densidade populacional e das espécies presentes no local (Faria et al., 2014).

A interferência da comunidade infestante pode reduzir a altura de inserção da primeira espiga, o comprimento e a circunferência das espigas, as fitomassas das espigas e dos grãos e a produção estimada da cultura (Rossi et al., 1996). A redução do rendimento da cultura, devido à competição estabelecida com as plantas daninhas, pode alcançar até $70 \%$ da sua produtividade potencial, variando em função de fatores relacionados à infestação daninha, ao ambiente e à cultura (Fancelli e Dourado-Neto, 2000).

$\mathrm{Na}$ cultura do milho, constataram-se períodos de convivência inicial das plantas daninhas e cultivadas entre 15 e 30 dias sem reduções na produção de grãos (Merotto Jr. et al., 2000). Por outro lado, Ramos e Pitelli (1994) verificaram que as plantas daninhas que emergiram na cultura, 
após os 42 dias da emergência do milho, não afetaram a produção de grãos.

A cultura do milho apresenta diversos híbridos, o que possibilita sua condução e produção em diferentes localidades. É sabido que a reação dos híbridos de milho a herbicidas pósemergentes é diferente quanto ao grau de seletividade (Nicolai et al., 2003). Entre os fatores determinantes da seletividade encontram-se: i) fatores relacionados às características ao herbicida, ou ao método de aplicação como dose, formulação, localização espacial ou temporal do herbicida em relação à planta; ii) fatores relacionados às características das plantas como seletividade associada à retenção e à absorção diferencial (idade das plantas, cultivar, tamanho da semente ou estrutura de propagação vegetativa); seletividade associada à translocação diferencial e; seletividade associada ao metabolismo diferencial (detoxificação); iii) presença de antídotos nas formulações (Oliveira Junior, 2001a).

A seletividade do herbicida definida como a resposta diferencial das espécies de plantas a um determinado herbicida é a base para o sucesso do controle químico de plantas daninhas na produção agrícola (Oliveira Junior, 2001b). A seletividade dos herbicidas às plantas cultivadas possibilita o controle na linha sem causar danos ao sistema radicular e a alta operacionalidade em grandes áreas (Victória Filho, 2003). Evidências fisiológicas e genéticas indicam que, freqüentemente, o principio determinante da seletividade em plantas é a capacidade de autodesintoxicação pela metabolização do herbicida, por ação enzimática (Alves et al., 2003).

Entre os herbicidas mais utilizados na cultura do milho, e há mais tempo, destaca-se a atrazine, pertencente ao grupo químico das triazinonas, cujo mecanismo de ação é a inibição do fotossistema II. O sitio de ação desse herbicida é na membrana do tilacóide, onde ocorre a fase fotoquímica da fotossíntese, mais especificamente no transporte de elétrons. Uma planta é mais susceptível a esse herbicida, se o mesmo acoplar-se ao composto $Q_{b}$ (quinona b) componente do fotossistema II e, assim, impossibilitando o transporte de elétrons aos demais componentes da cadeia, impedindo assim, a produção de ATP e de NADPH. Na cultura do milho, a atrazine, é amplamente utilizada em pós-emergência, sendo degradada nesta planta pela metabolização do herbicida (desativação fisiológica), especialmente pelo processo de conjugação com glutationa nas folhas, o que faz com que o herbicida nunca chegue ao cloroplasto para causar injúrias. Essa molécula, nas doses recomendadas, é totalmente seletiva ao milho, sem restrição a qualquer híbrido (López-Ovejero et al., 2003b).

Dentre os mais recentes herbicidas registrados para a cultura do milho encontra-se o mesotrione, pertencente ao grupo químico das tricetonas. É classificado como herbicida seletivo, com aplicação em pós-emergência, para o controle de folhas largas anuais e gramíneas na cultura do milho. O modo de ação do mesotrione consiste na inibição da biossíntese de carotenóides através da interferência na atividade da enzima HPPD (4-hidroxifenilpiruvato-dioxigenase) nos cloroplastos. Os sintomas fitotóxicos envolvem o branqueamento das plantas sensíveis com posterior necrose e morte dos tecidos vegetais em cerca de 1 a 2 semanas. O milho é tolerante ao 
mesotrione devido à sua capacidade de metabolizar rapidamente o herbicida, produzindo metabólicos sem atividade, o que não ocorre nas plantas daninhas (Bachiega e Soares, 2002)

Alguns herbicidas utilizados isoladamente podem não ser suficientes para eliminar a interferência das plantas daninhas nas culturas, exigindo medidas integradas de manejo ou a mistura destes produtos, buscando um efeito aditivo dos mesmos (Jakelaitis et al., 2005). A combinação de mesotrione com atrazine apresenta efeitos sinergístico e aditivos desejáveis, com a possibilidade de uso de doses menores de ambos os produtos, e a ampliação do espectro de controle em pós-emergência de importantes espécies de plantas daninhas de folhas largas e estreitas (Bachiega e Soares, 2002).

Cataneo et al. (2004) trabalhando com sete híbridos, observaram que a maioria deles apresenta fitotoxicidade quando da aplicação de mesotrione + atrazine (mistura em tanque) em pósemergência, porém este efeito não excedeu em nenhum dos casos $10 \%$, uma porcentagem aceitável.

A adição de adjuvantes, nutrientes ou inseticidas a calda contendo herbicida pode reduzir a capacidade da planta em tolerar o herbicida, tendo como consequência a redução da seletividade para a cultura do milho e eficácia no controle das plantas daninhas (Gassen, 2002). Dentre as inovações tecnológicas para o controle de plantas daninhas na cultura do milho está o conhecimento da dinâmica dos herbicidas em condições de pós-emergência juntamente com outros agroquímicos (Christoffoleti e Mendonça, 2001).

Nos agroecossistemas brasileiros onde se cultiva milho, além da constante presença das plantas daninhas, a ocorrência de Spodoptera frugiperda é generalizada, prejudicando o desenvolvimento da planta e se caracterizando como a principal praga da cultura, atacando-a durante todo o ciclo. A lagarta-do-cartucho, como é popularmente conhecida, pode reduzir significativamente a produção e a qualidade de grãos, sendo controlada por meio da aplicação de inseticidas (Cruz, 2003).

Normalmente, a época de ataque da lagarta-do-cartucho no milho coincide com o momento do controle de plantas daninhas. Por isso, uma das preocupações de técnicos e produtores é conhecer as interações entre os diferentes produtos químicos (inseticidas $\mathrm{x}$ herbicidas) recomendados para a cultura. Aplicações de inseticidas e herbicidas podem ser feitas simultânea ou sequencialmente, o que possibilita a ocorrência de interações antagônicas, aditivas ou sinérgicas (Rahman e James, 1993). Segundo Nasser (2006) a mistura de inseticidas (chlorpirifos ou lufenuron ou methomyl) e herbicidas (mesotrione + atrazine) não alteram os níveis de controle das plantas daninhas no início da cultura do milho. Interações sinérgicas foram observadas entre o herbicida nicosulfuron (grupo das sulfoniluréias) e o inseticida clopirifós (grupo dos organofosforados), no entanto, com severas injúrias à cultura do milho (Rahman e James, 1993). O trabalho realizado por Nasser (2006) demonstrou que na cultura do milho os inseticidas causam maior redução de seletividade ao herbicida, tornando-se fitotóxicos. 
A condição de um sistema produtivo, sobretudo quando em áreas extensas, nem sempre possibilita a adoção de todas as recomendações agrícolas de forma individualizada e no momento correto. Assim, a aplicação de herbicidas e inseticidas, por vezes, pode ocorrer em intervalo muito curto de tempo ou mesmo simultaneamente. Trabalhos científicos relatam a interação negativa entre herbicidas inibidores da enzima ALS, com inseticidas organofosforados, na cultura de milho (Silva et al., 2005a e 2005b).

Dentre os fatores bióticos que interferem na cultura do milho, as plantas daninhas podem causar perdas de rendimento de até $70 \%$. Neste caso, o controle de plantas daninhas é uma necessidade de ordem econômica, em que o método químico, por meio de herbicidas, é o mais viável (López-Ovejero et al., 2003a). Neste contexto, associações de herbicidas com inseticidas são utilizadas para reduzir o número de operações na lavoura, resultando em redução dos custos operacionais e injúrias causadas à cultura pelo tráfego de máquinas. Entretanto, herbicidas podem interagir sinergicamente com outras substâncias, potencializando a fitotoxicidade às plantas cultivadas, tornando-se necessário a realização de estudos sobre possíveis interações entre os agroquímicos, para orientar o produtor. Com este intuito, o trabalho objetivou estudar a interação entre herbicidas aplicados em mistura com inseticidas no desenvolvimento e produtividade de híbridos de milho.

\section{MATERIAL E MÉTODOS}

O experimento foi conduzido em área experimental da Fazenda Escola Capão da Onça, pertencente à Universidade Estadual de Ponta Grossa - UEPG, localizada no município de Ponta Grossa/PR, no período de novembro a abril. O solo da área é classificado como Cambissolo Háplico Distrófico de textura média e com as propriedades físico-químicas apresentadas na Tabela 1.

TABELA 1. Características físico-químicas do solo (0-20 cm). UEPG, Ponta Grossa-PR.

\begin{tabular}{ccc|ccccc|c|ccc}
\hline $\mathbf{M . O}$ & $\mathbf{p H}$ & $\mathbf{P}$ & $\mathbf{K}^{+}$ & $\mathbf{C a}^{++}$ & $\mathbf{M g}^{++}$ & $\mathbf{H}^{+}+\mathbf{A l}^{+3}$ & $\mathbf{C T C}$ & $\mathbf{V}$ & Argila & Silte & Areia \\
\hline $\mathrm{g} \mathrm{dm}^{-3}$ & $\mathrm{CaCl}_{2}$ & $\mathrm{mg} \mathrm{dm}^{-3}$ & \multicolumn{6}{c}{$\mathrm{Cmol}_{\mathrm{c}} \mathrm{dm}^{-3}$} & & $(\%)$ & \multicolumn{2}{c|}{$\mathrm{g} \mathrm{kg}^{-1}$} & \\
\hline- & 4,6 & 5,4 & 0,32 & 3,5 & 2,0 & 8,36 & 6,12 & 41 & - & - & - \\
\hline
\end{tabular}

O delineamento experimental adotado foi o de blocos casualizados, em esquema fatorial $3 \times 2 \times 2$, onde três combinações de herbicidas, associadas a dois inseticidas e dois híbridos de milho, totalizaram 12 tratamentos (Tabela 2). As unidades experimentais 
constituíram-se de quatro linhas espaçadas de 0,8 m, com $6 \mathrm{~m}$ de comprimento, totalizando $19,2 \mathrm{~m}^{2}$ de área.

Os híbridos utilizados foram Pioneer 30P70 e 30K75. O híbrido 30P70 é tipo simples, precoce, grão amarelo-alaranjado, semiduro, sendo recomendada a população de 50 a 60 mil plantas por hectare, para espaçamento de 0,80 a 0,90m. De acordo com o fabricante seu plantio é recomendado para o Sul do país no período normal de cultivo e safrinha. O híbrido 30K75 é tipo simples, semiprecoce, grão alaranjado, semiduro, sendo recomendada a população de 55 a 65 mil plantas por hectare, para espaçamento de 0,80 a $0,90 \mathrm{~m}$. De acordo com o fabricante seu plantio é recomendado para o Sul do país no período normal e tardio de cultivo, e safrinha.

TABELA 2. Tratamentos utilizados no experimento. UEPG, Ponta Grossa-PR.

\begin{tabular}{|c|c|c|c|c|}
\hline \multicolumn{2}{|r|}{ Tratamentos } & \multirow{2}{*}{ Nome comercial } & Dose i.a. & Dose p.c. \\
\hline Híbridos-Milho & Produtos & & $\left(g_{h a^{-1}}\right)$ & $\left(\mathrm{L} \mathrm{ha}^{-1}\right)$ \\
\hline 30P70 & $\begin{array}{l}\text { mesotrione+lufenuron } \\
\text { mesotrione+methomyl } \\
\text { atrazine+lufenuron } \\
\text { atrazine+methomyl } \\
\text { (mesotr+atraz)+lufenuron } \\
\text { (mesotr+atraz)+methomyl }\end{array}$ & $\begin{array}{c}\text { Callisto+Match } \\
\text { Callisto+Lannate } \\
\text { Siptram+Match } \\
\text { Siptram+Lannate } \\
\text { Callisto+Siptram+Match } \\
\text { Callisto+Siptram+Lannate }\end{array}$ & $\begin{array}{c}120+15 \\
120+129 \\
1250+15 \\
1250+129 \\
120+1250+15 \\
120+1250+129\end{array}$ & $\begin{array}{c}0,25+0,3 \\
0,25+0,6 \\
2,5+0,3 \\
2,5+0,6 \\
0,25+2,5+0,3 \\
0,25+2,5+0,6\end{array}$ \\
\hline $30 K 75$ & $\begin{array}{c}\text { mesotrione+lufenuron } \\
\text { mesotrione+methomyl } \\
\text { atrazine+lufenuron } \\
\text { atrazine+methomyl } \\
\text { (mesotr+atraz)+lufenuron } \\
\text { (mesotr+atraz)+methomyl }\end{array}$ & $\begin{array}{c}\text { Callisto+Match } \\
\text { Callisto+Lannate } \\
\text { Siptram+Match } \\
\text { Siptram+Lannate } \\
\text { Callisto+Siptram+Match } \\
\text { Callisto+Siptram+Lannate }\end{array}$ & $\begin{array}{c}120+15 \\
120+129 \\
1250+15 \\
1250+129 \\
120+1250+15 \\
120+1250+129\end{array}$ & $\begin{array}{c}0,25+0,3 \\
0,25+0,6 \\
2,5+0,3 \\
2,5+0,6 \\
0,25+2,5+0,3 \\
0,25+2,5+0,6\end{array}$ \\
\hline
\end{tabular}

i.a. = ingrediente ativo; p.c. $=$ produto comercial 
Os produtos foram aplicados com um pulverizador costal pressurizado por $\mathrm{CO}_{2}$, com pressão constante de 3,0 bar. A barra de aplicação era constituída com seis bicos do tipo leque, modelo Turbo Teejet 110.02. O volume de calda aplicado foi de $200 \mathrm{~L} \mathrm{ha}^{-1}$. A descrição dos produtos utilizados encontra-se na Tabela 3.

TABELA 3. Caracterização dos inseticidas e herbicidas utilizados no experimento. UEPG, Ponta Grossa-PR.

\begin{tabular}{|c|c|c|c|c|c|c|}
\hline \multicolumn{7}{|c|}{ INSETICIDAS } \\
\hline Controle/sobre & $\begin{array}{c}\text { Ingrediente } \\
\text { ativo }\end{array}$ & $\begin{array}{c}\text { Nome } \\
\text { comercial }\end{array}$ & Form. & $\begin{array}{c}\text { Classe } \\
\text { Toxicológica }\end{array}$ & $\begin{array}{c}\text { Concentração } \\
(\mathrm{g} \text { i.a L-1) }\end{array}$ & $\begin{array}{c}\text { Dose recomendada } \\
(\text { p.c. ha-1) }\end{array}$ \\
\hline Spodoptera & lufenuron & Match CE & $\overline{C E}$ & IV & 50 & $0,3 \mathrm{~L}$ \\
\hline frugiperda & methomyl & Lannate BR & $\mathrm{SC}$ & $\mathrm{T}$ & 215 & $0,6 \mathrm{~L}$ \\
\hline \multicolumn{7}{|c|}{ HERBICIDAS } \\
\hline Controle/sobre & $\begin{array}{c}\text { Ingrediente } \\
\text { ativo }\end{array}$ & $\begin{array}{l}\text { Nom } \\
\text { comer }\end{array}$ & & Formulação & $\begin{array}{c}\text { Concentração } \\
(\mathrm{g} \text { i.a L-1) }\end{array}$ & $\begin{array}{c}\text { Dose recomendada } \\
\text { (p.c./ha) }\end{array}$ \\
\hline $\begin{array}{c}\text { Brachiaria plantaginea; } \\
\text { Chenopodium album L.; } \\
\text { Euphorbia heterophylla } \\
\text { L; Sida cordifolia L.; }\end{array}$ & Mesotrione & Callis & & SC & 480 & $0,3-0,4 \mathrm{~L}$ \\
\hline $\begin{array}{c}\text { Ipomoea sp.; Digitaria } \\
\text { horizontalis; Commelina } \\
\text { virginica }\end{array}$ & atrazine & Siptra & & SC & 500 & $0,3 \mathrm{~kg}$ \\
\hline
\end{tabular}

O experimento foi instalado em área sob sistema plantio direto, tendo permanecido em pousio durante o inverno. Efetuou-se a dessecação da vegetação com glyphosate (1,5 $\mathrm{L} \mathrm{ha}^{-1}$ ), aos 38 dias antes da semeadura, e aplicação complementar aos quatro dias antes da semeadura. A cultura de milho foi conduzida em sistema de plantio direto, sendo a semeadura realizada em 13 de novembro de 2006. O espaçamento utilizado foi de 0,80 m com 5,58 sementes por metro na linha, visando obter uma média de aproximadamente

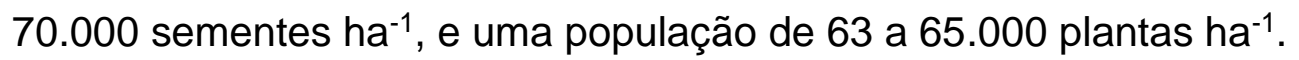

A adubação de base, realizada no instante da semeadura foi de $300 \mathrm{~kg} \mathrm{ha}^{-1}$, da fórmula 10.20.20. A adubação em cobertura foi realizada quando a cultura do milho encontrava-se no estádio V5, com quatro a seis folhas expandidas (37 dias após a semeadura), com $200 \mathrm{~kg} \mathrm{ha}^{-1}$ de uréia, fornecendo $90 \mathrm{~kg} \mathrm{ha}^{-1}$ de $\mathrm{N}$.

A aplicação dos tratamentos (Tabela 2) foi realizada aos 36 dias após a semeadura 
(DAS), durante a manhã, sob temperatura de $22^{\circ} \mathrm{C}$ e com o céu parcialmente encoberto, quando a cultura de milho apresentava com 4 e 6 folhas expandidas. Todas as unidades experimentais, após a aplicação dos tratamentos, foram mantidas livres da competição de plantas daninhas por meio de duas capinas manuais, objetivando evitar a interferência destas sobre a cultura. Eventuais plantas daninhas que emergiram, não causaram interferência na produtividade da cultura. A colheita do milho foi realizada aos 152 dias do ciclo. A produtividade foi estimada pela colheita das duas linhas centrais da parcela totalizando uma área útil de $6,4 \mathrm{~m}^{2}$.

As variáveis avaliadas foram: altura de plantas, número de folhas expandidas e diâmetro de colmo aos 0, 16, 32 e 40 DAA (dias após aplicação dos produtos); teor de clorofila nas folhas aos 0 e 24 DAA; fitotoxicidade aos 8, 16, 24 DAA; número de espigas e altura de inserção da primeira espiga aos 56 DAA. As medições de altura de plantas, número de folhas expandidas, diâmetro de colmo, número de espigas e altura de inserção da primeira espiga foram realizadas medindo-se cinco plantas, aleatoriamente, por parcela. O teor de clorofila foi realizado, utilizando clorofilômetro Minolta SPAD-502, medindo-se em 5 plantas por parcela, na última folha expandida, no terço médio da folha. A fitotoxicidade foi avaliada por meio de escala percentual de danos causados nas plantas de milho. $O$ número de espigas e altura de inserção da primeira espiga foi realizado medindo-se 5 plantas por parcela.

Após a colheita, foram avaliados: tamanho de espiga, diâmetro de espiga, número de fileiras por espiga e número de grãos por fileira, fitomassa de 1000 grãos, teor de água e fitomassa total de grãos por parcela. O tamanho de espigas, diâmetro de colmo, número de fileiras e número de grãos por fileira foram avaliados antes da debulha das espigas, tomando-se 5 espigas por parcela. Após a debulha foi medida a fitomassa total de grãos da área útil de cada parcela e, posteriormente a umidade de grãos, procedendo-se a padronização para $13 \%$.

Os dados obtidos foram submetidos à análise de variância pelo teste de F. Quando constatadas diferenças estatísticas, as médias foram comparadas pelo teste Tukey ( $P>$ 0,05), utilizando o programa ASSISTAT 7.7 beta (Silva e Azevedo, 2009).

\section{RESULTADOS E DISCUSSÃO}

Considerando que os herbicidas atrazine e/ou mesotrione foram aplicados em todos os tratamentos, nos dois híbridos de milho, admite-se que toda diferença existente entre os tratamentos seja pela presença dos inseticidas lufenuron ou metomyl. 
O híbrido de milho 30P70 apresentou os maiores valores de altura de plantas (AP), em todas as épocas avaliadas, não evidenciando efeito diferenciado de AP para as misturas de herbicidas e inseticidas testados (Tabela 4). Este mesmo híbrido apresentou maior número de folhas por planta de milho (NFP), em todas as avaliações, com exceção da época 32 DAA, em que os dois híbridos apresentaram NFP equivalentes.

O híbrido 30P70 tem população recomendada para espaçamentos entre 0,80 a $0,90 \mathrm{~m}$ entre 50 a 60.000 plantas ha-1. Entretanto, utilizou-se aproximadamente 70.000 sementes ha-1, visando obter entre 63 e 65.000 plantas ha-1, população esta superior a indicada (Tabela 4). O adensamento do híbrido de milho 30P70 pode ter aumentado a competição intraespecífica, principalmente por luz, favorecendo o crescimento em extensão de milho (Balbinot Jr. e Fleck, 2005). Para o híbrido $30 K 75$ foi utilizada a população de 55 a 65.000 plantas ha-1, a qual é a recomendada para o espaçamento de 0,80 a 0,90m, não causando competição intraespecífica e possibilitando crescimento normal da cultura do milho.

TABELA 4. Número de folhas por planta (NFP) e altura de plantas de milho (AP) influenciadas por herbicidas, inseticidas e híbridos. UEPG, Ponta Grossa-PR.

\begin{tabular}{|c|c|c|c|c|c|c|c|c|}
\hline \multirow[b]{2}{*}{ Tratamentos } & \multicolumn{4}{|c|}{ NFP } & \multicolumn{4}{|c|}{$\mathrm{AP}(\mathrm{m})$} \\
\hline & 0 DAA $^{1}$ & 16 DAA & 32 DAA & 40 DAA & $0 \mathrm{DAA}^{1}$ & 16 DAA & 32 DAA & 40 DAA \\
\hline \multicolumn{9}{|l|}{ Herbicidas } \\
\hline mesotrione & $5,7 a^{2}$ & $7,2 \mathrm{a}$ & $11,7 \mathrm{a}$ & $14,8 \mathrm{a}$ & $0,88 a^{2}$ & $1,76 a$ & $2,29 b$ & $2,50 \mathrm{a}$ \\
\hline atrazine & 5,5 a & 7,4 a & $11,1 \quad b$ & 14,8 a & 0,86 a & $1,72 \mathrm{a}$ & $2,30 \quad a$ & 2,51 a \\
\hline mes+atraz & 5,5 a & 7,3 a & $11,3 a b$ & $14,8 \mathrm{a}$ & $0,87 a$ & $1,71 \mathrm{a}$ & $2,30 \quad a$ & 2,48 a \\
\hline \multicolumn{9}{|l|}{ Inseticidas } \\
\hline lufenuron & 5,6 a & 7,3 a & $11,3 \mathrm{a}$ & $14,7 \quad b$ & $0,85 \mathrm{a}$ & $1,72 \mathrm{a}$ & $2,31 \quad a$ & $2,52 a$ \\
\hline metomyl & 5,5 a & 7,3 a & $11,5 \mathrm{a}$ & $14,9 a$ & 0,88 a & $1,74 a$ & $2,29 a$ & 2,48 a \\
\hline \multicolumn{9}{|l|}{ Híbridos } \\
\hline $30 P 70$ & 5,9 a & 7,4 a & $11,8 \quad a$ & $14,9 a$ & $0,95 a$ & $1,83 \mathrm{a}$ & $2,48 \quad a$ & $2,69 a$ \\
\hline $30 K 75$ & $5,3 \quad b$ & $7,2 \quad b$ & 11,0 a & $14,7 \quad b$ & $0,78 \quad b$ & $1,63 \quad b$ & $2,12 \quad \mathbf{b}$ & $2,30 \quad b$ \\
\hline CV (\%) & 11,5 & 5,0 & 4,7 & 1,5 & \begin{tabular}{|l|}
7,03 \\
\end{tabular} & 4,44 & 6,15 & 2,62 \\
\hline
\end{tabular}

Observou-se que, aos 32 DAA, a AP e o NFP de milho foram significativamente maiores quando tratadas com o herbicida mesotrione, em mistura com qualquer um dos inseticidas testados, nos dois híbridos. Na mesma ocasião, as plantas com menor AP e NFP foram aquelas tratadas com o herbicida atrazine, em mistura com qualquer um dos inseticidas testados, para os dois híbridos. 
O herbicida atrazine, cujo mecanismo de ação é a inibição do fotossistema II, pode afetar o desenvolvimento do milho quando aplicado fora do estádio ideal, uma vez que as plantas aumentam a capacidade de metabolização do herbicida à medida que se desenvolvem.

Aos 40 DAA, observou-se interação significativa entre inseticidas e herbicidas, para AP, e interação significativa entre os herbicidas testados para a variável NFP nos dois híbridos avaliados (Tabela 5). Ou seja, o comportamento dos herbicidas variou em relação aos inseticidas, e o efeito das misturas foi diferente entre os tratamentos testados.

TABELA 5. Desdobramento dos efeitos, da interação entre herbicidas, inseticidas e híbridos de milho, sobre o número de folhas por planta (NFPPM) aos 40 DAA; e da interação entre herbicidas e híbridos de milho, sobre a altura de plantas (APM) aos 40 DAA. UEPG, Ponta Grossa-PR.

\begin{tabular}{|c|c|c|c|c|c|c|c|c|c|c|c|c|c|}
\hline \multirow{3}{*}{ Tratamentos } & \multicolumn{6}{|c|}{ NFP aos 40 DAA } & \multicolumn{7}{|c|}{ AP aos 40 DAA $(\mathrm{m})$} \\
\hline & \multicolumn{6}{|c|}{ Híbridos } & \multicolumn{7}{|c|}{ Híbridos } \\
\hline & \multicolumn{3}{|c|}{$30 P 70$} & \multicolumn{3}{|c|}{$30 K 75$} & \multicolumn{3}{|c|}{ 30P70 } & \multicolumn{4}{|c|}{$30 K 75$} \\
\hline \multicolumn{14}{|l|}{ Herbicidas } \\
\hline mesotrione & 14,8 & a & $A$ & 14,8 & a & $A$ & 2,69 & $a b$ & $A$ & 2,32 & a & B & \\
\hline atrazine & 15,0 & $\mathrm{a}$ & $A$ & 14,6 & a & $B$ & 2,75 & a & $A$ & 2,28 & a & B & \\
\hline mes + atraz & 14,9 & a & $A$ & 14,8 & a & $A$ & 2,64 & b & $A$ & 2,32 & a & B & \\
\hline \multicolumn{14}{|l|}{ Inseticidas } \\
\hline lufenuron & 14,9 & a & $A$ & 14,5 & b & B & -- & -- & -- & -- & -- & & -- \\
\hline metomyl & 14,9 & a & $A$ & 14,9 & $\mathrm{a}$ & A & -- & -- & -- & -- & -- & & -- \\
\hline
\end{tabular}

DAA = dias após a aplicação dos herbicidas.

Médias seguidas da mesma letra minúscula, comparadas na coluna, e letra maiúscula, comparadas na linha, não diferem estatisticamente entre si pelo teste de Tukey $(P>0.05)$.

O híbrido de milho 30P70 apresentou AP significativamente maior na presença de todos herbicidas, quando comparado ao híbrido 30K75. As plantas do híbrido 30P70 apresentaram AP equivalentes quando tratadas com mesotrione ou atrazine. Todavia, as plantas que receberam atrazine + mesotrione em mistura em tanque sofreram significativa redução na AP, para qualquer inseticida utilizado. O NFP aos 40 DAA foi significativamente menor para o híbrido $30 \mathrm{~K} 75$, quando tratado com o herbicida atrazine em mistura com lufenuron (Tabela 5). 
O diâmetro de colmo (DC) das plantas de milho aos 16 DAA foi menor quando do uso do herbicida atrazine em mistura com os inseticidas, para os dois híbridos. No entanto, o desenvolvimento do colmo se deu de forma equivalente, nas avaliações seguintes (Tabela 6). De forma semelhante, o inseticida lufenuron reduziu o DC quando em mistura com qualquer um dos herbicidas testados, equivalendo-se nas avaliações subsequentes (Tabela 6).

TABELA 6. Diâmetro de colmo (DC) e teor de clorofila (TC) em plantas de milho influenciadas por herbicidas, inseticidas e híbridos. UEPG, Ponta Grossa-PR.

\begin{tabular}{|c|c|c|c|c|c|c|c|}
\hline \multirow{2}{*}{ Tratamentos } & \multicolumn{4}{|c|}{$\mathrm{DC}(\mathrm{cm})$} & \multicolumn{3}{|c|}{$\mathrm{TC}\left(\mathrm{mg} \mathrm{dm}^{-2}\right)$} \\
\hline & 0 DAA $^{1}$ & 16 DAA & 32 DAA & 40 DAA & 0 DAA $^{1}$ & 24 & DAA \\
\hline \multicolumn{8}{|l|}{ Herbicidas } \\
\hline mesotrione & $1,55 a^{2}$ & $2,04 a$ & $2,16 a$ & $2,16 a$ & $44,0 \quad a^{2}$ & 47,5 & a \\
\hline atrazine & $1,52 a$ & $1,95 \quad b$ & 2,16 a & $2,14 a$ & $41,2 \mathrm{a}$ & 49,2 & a \\
\hline mês + atr & $1,48 \mathrm{a}$ & $2,05 a$ & $2,14 a$ & $2,19 a$ & $42,9 a$ & 48,6 & a \\
\hline \multicolumn{8}{|l|}{ Inseticidas } \\
\hline lufenuron & $1,53 a$ & $2,03 a$ & $2,12 \quad b$ & $2,16 a$ & 43,6 a & 48,2 & $a$ \\
\hline metomyl & $1,50 \mathrm{a}$ & $2,00 \mathrm{a}$ & $2,19 a$ & $2,16 a$ & 43,1 a & 48,6 & a \\
\hline \multicolumn{8}{|l|}{ Híbridos } \\
\hline 30 P70 & $1,61 \mathrm{a}$ & $2,02 a$ & $2,13 a$ & $2,16 \mathrm{a}$ & 43,3 a & 48,3 & a \\
\hline $30 \mathrm{~K} 75$ & $1,42 \quad b$ & $2,01 \quad a$ & $2,18 a$ & $2,16 a$ & $43,4 a$ & 48,5 & a \\
\hline CV (\%) & 12,22 & 5,22 & 5,35 & 4,68 & 5,66 & 4,53 & \\
\hline
\end{tabular}

${ }^{1}$ DAA $=$ dias após a aplicação dos herbicidas.

${ }^{2}$ Médias seguidas da mesma letra, comparadas na coluna, não diferem estatisticamente entre si pelo teste de Tukey ( $\left.P>0.05\right)$.

Os teores de clorofila (TC) no tecido foliar das plantas de milho, como era de se esperar, devido ao crescimento das plantas, apresentaram-se maiores aos 24 DAA, em relação à medida efetuada no dia da aplicação dos produtos (0 DAA). Dentre os tratamentos testados, não foram encontradas diferenças entre os TC nas plantas de milho aos 24 DAA (Tabela 6). Jakelaitis et al. (2005) encontraram menores TC em plantas de milho tratadas com atrazine. Segundo Zagonel et 
al. (2000), menores TC e menor produção de grãos foram obtidos em milho tratado com nicosulfuron em mistura com foramsulfuron + iodosulfuron.

De modo geral, a toxicidade das misturas testadas sobre os híbridos de milho foi baixa. Verificou-se fitotoxidez baixa pela aplicação de herbicidas seletivos, desaparecendo após 24 DAA, evidenciando a recuperação da cultura (Tabela 7). Em milho tratado com herbicida nicosulfuron e inseticidas foram sulfuron + iodosulfuron foram observadas injúrias leves à cultura, porém com rápida recuperação (Jakelaitis et al., 2005 e Zagonel et al., 2002). Cataneo et al. (2004) avaliaram o comportamento seletivo da mistura (mesotrione + atrazine) sobre os híbridos de milho P30F33, P32R21, BKB350, XL215, Flash e Attack, observando injúrias sobre a maioria destes híbridos, porém não excedendo 10\%, porcentagem aceitável.

TABELA 7. Médias das avaliações visuais dos sintomas de fitotoxicidade nas plantas de milho, em diferentes épocas após a aplicação dos produtos, milho influenciadas porherbicidas, inseticidas e híbridos. UEPG, Ponta Grossa-PR.

\begin{tabular}{|c|c|c|c|c|c|c|}
\hline \multicolumn{3}{|c|}{ Tratamentos } & \multicolumn{4}{|c|}{ FITOTOXICIDADE ${ }^{2}$} \\
\hline Híbrid & Vilho & Produtos & 8 DAA $^{1}$ & 16 DAA & 24 DAA & Média \\
\hline \multirow{6}{*}{$30 \mathrm{P} 70$} & 1 & mesotrione + lufenuron & 6,5 & 4,0 & 3,0 & 4,5 \\
\hline & 2 & mesotrione + methomyl & 11,3 & 7,8 & 7,3 & 8,8 \\
\hline & 3 & atrazine + lufenuron & 12,0 & 10,3 & 9,8 & 10,7 \\
\hline & 4 & atrazine + methomyl & 9,5 & 11,3 & 5,3 & 8,7 \\
\hline & 5 & $($ mesotr + atraz $)+$ lufenuron & 11,3 & 6,5 & 3,5 & 7,1 \\
\hline & 6 & (mesotr + atraz)+methomyl & 8,8 & 7,5 & 3,5 & 6,6 \\
\hline \multirow{6}{*}{$30 K 75$} & 7 & mesotrione + lufenuron & 13,8 & 7,5 & 3,5 & 8,3 \\
\hline & 8 & mesotrione + methomyl & 12,5 & 10,0 & 7,8 & 10,1 \\
\hline & 9 & atrazine + lufenuron & 17,5 & 12,5 & 12,0 & 14,0 \\
\hline & 10 & atrazine + methomyl & 13,8 & 8,3 & 4,0 & 8,7 \\
\hline & 11 & $($ mesotr + atraz) + lufenuron & 16,3 & 12,0 & 10,8 & 13,0 \\
\hline & 12 & (mesotr + atraz)+methomyl & 12,5 & 11,3 & 7,0 & 10,3 \\
\hline
\end{tabular}

${ }^{1} \mathrm{DAA}=$ dias após a aplicação dos herbicidas.

${ }^{3}$ Escala de Fitotoxicidade (SBCPD, 1995), onde 0\% equivale a plantas sem injúrias ou nenhum sintoma visível, e 100\% equivale a injúrias muito severas, sem recuperação da cultura. 
Por meio da avaliação visual da fitotoxicidade, verifica-se que os valores de fitotoxicidade foram, em sua maioria, maiores aos 8 DAA e vão diminuindo gradativamente, até chegarem aos valores mais baixos aos 24 DAA. Correlacionando-se os valores de fitotoxicidade aos 8 DAA com a produtividade real média de cada tratamento, nota-se que a fitotoxicidade não afetou a produtividade, uma vez que o valor do coeficiente de determinação $\left(R^{2}\right)$ foi baixo, demonstrando que somente $21 \%$ desse efeito pode ser explicado pela equação ajustada (Figura 2).

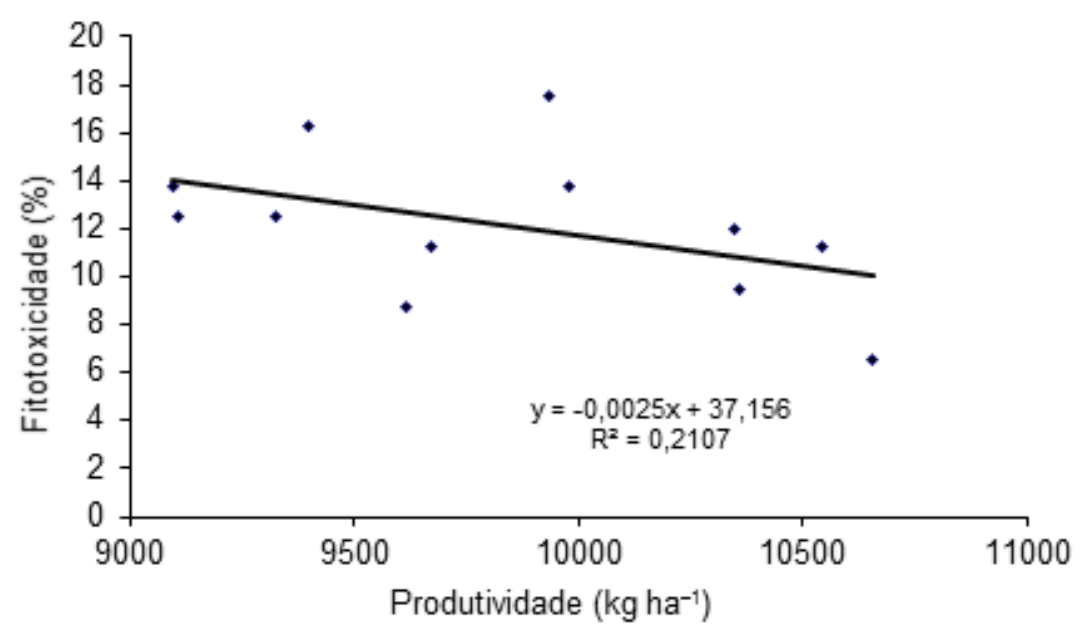

FIGURA 2. Correlação entre produtividade e fitotoxicidade entre os híbrido 30P70 e 30K75. UEPG, Ponta Grossa-PR.

O número de espigas por planta (NEP), diâmetro de espigas (DE), número de fileiras por espiga (NFE) e número de grãos por fileira (NGF) não foram afetados pelas misturas de herbicidas e inseticidas testadas (Tabela 8). Contrariando o trabalho realizado por Nasser (2006), o qual comprovou na cultura do milho que os inseticidas causaram redução significativa de seletividade ao herbicida. Diferenças, nestas variáveis foram evidenciadas entre os híbridos testados (Tabela 8). Este comportamento diferenciado entre os híbridos é decorrente, provavelmente, de suas distintas características genéticas e morfológicas.

De acordo com a fitomassa seca de plantas daninhas, apesar de não diferirem estatisticamente, ocorreu uma tendência da mistura entre atrazine e mesotrione apresentarem um sinergismo no seu controle, enquanto que a adição de metomyl apresentou uma tendência ao antagonismo (Tabela 8), fato observado também por Bachiega e Soares (2002). Contudo, observouse que existiu diferença no controle de plantas daninha entres os híbridos, o que vem a mostrar que as características de NFP e AP do híbrido 30P70 (Tabela 8) podem estar influenciando na eficiência do controle. 
TABELA 8. Componentes da produção, plantas daninhas presentes na pré-colheita e produtividade de milho influenciados por herbicidas, inseticidas e híbridos. UEPG, Ponta Grossa-PR.

\begin{tabular}{|c|c|c|c|c|c|c|c|c|c|c|c|c|c|c|c|c|}
\hline $\begin{array}{c}\text { Tratamentos } \\
\text { Herbicidas }\end{array}$ & \multicolumn{2}{|c|}{ NEP } & \multicolumn{2}{|c|}{$\mathrm{DE}(\mathrm{cm})$} & \multicolumn{2}{|c|}{ NFE } & \multicolumn{2}{|c|}{ NGF } & \multicolumn{2}{|c|}{ FMMG (g) } & \multicolumn{2}{|c|}{ AIPE (m) } & \multicolumn{2}{|c|}{$\begin{array}{c}\text { FMSPD }^{2} \\
\left(\mathrm{~g} \mathrm{~m}^{-2}\right)\end{array}$} & \multicolumn{2}{|c|}{$\begin{array}{l}\text { Produtividade } \\
\qquad\left(\mathbf{k g ~ h a}^{-1}\right)\end{array}$} \\
\hline & & & & & & & & & & & & & & & & \\
\hline mesotrione & 1,76 & $a^{1}$ & 4,7 & $\mathrm{a}$ & 13,6 & a & 38,7 & $a$ & 335,4 & $\mathrm{a}$ & 1,11 & $a$ & 25,9 & $\mathrm{a}$ & 10.072 & a \\
\hline atrazine & 1,71 & $\mathrm{a}$ & 4,7 & $\mathrm{a}$ & 13,6 & a & 39,6 & $\mathrm{a}$ & 333,0 & $a b$ & 1,09 & a & 24,2 & $a$ & 9.933 & $a$ \\
\hline mes + atr & 1,76 & $\mathrm{a}$ & 4,7 & $\mathrm{a}$ & 13,7 & a & 38,2 & $a$ & 318,8 & $\mathrm{~b}$ & 1,12 & a & 21,7 & $a$ & 9.503 & $a$ \\
\hline Inseticidas & & & & & & & & & & & & & & & & \\
\hline lufenuron & 1,73 & $\mathrm{a}$ & 4,7 & a & 13,6 & $\mathrm{a}$ & 38,7 & $a$ & 328,0 & $\mathrm{a}$ & 1,12 & $\mathrm{a}$ & 21,9 & $a$ & 9.998 & a \\
\hline metomyl & 1,76 & $\mathrm{a}$ & 4,7 & $\mathrm{a}$ & 13,7 & $a$ & 38,9 & $a$ & 330,1 & $\mathrm{a}$ & 1,10 & $a$ & 25,9 & $\mathrm{a}$ & 9.674 & a \\
\hline Híbridos & & & & & & & & & & & & & & & & \\
\hline $30 P 70$ & 1,91 & $\mathrm{a}$ & 4,6 & $b$ & 12,8 & $a$ & 41,2 & $a$ & 330,5 & $\mathrm{a}$ & 1,16 & a & 20,1 & $b$ & 10.199 & a \\
\hline $30 K 75$ & 1,58 & $b$ & 4,8 & $\mathrm{a}$ & 14,5 & $b$ & 36,5 & $b$ & 327,6 & $\mathrm{a}$ & 1,06 & $b$ & 27,8 & $a$ & 9.473 & b \\
\hline$\overline{C V}(\%)$ & 13,67 & & 2,92 & & 4,13 & & 5,47 & & 5,18 & & 6,99 & & 19,46 & & 9.85 & \\
\hline
\end{tabular}

'Médias seguidas da mesma letra, comparadas na coluna, não diferem estatisticamente entre si pelo teste de Tukey $(P>0.05)$.

${ }^{2}$ ANAVA realizada com os dados transformados para $\sqrt{ } x+2.0$.

$\mathrm{NEP}=$ número de espigas por planta; $\mathrm{DE}=$ diâmetro de espiga; $\mathrm{NFE}=$ número de fileiras por espiga; $\mathrm{NGF}=$ número de grãos por fileira; $F M M G=$ fitomassa de 1000 grãos; AIPE= altura de inserção da primeira espiga; FMSPD= fitomassa seca de plantas daninhas.

Em relação à fitomassa da parte aérea de plantas daninhas, as áreas cultivadas com o híbrido 30P70 apresentaram menor reinfestação (Tabela 8), lembrando que esta avaliação foi realizada às vésperas da colheita, após toda a área experimental ter sido submetida a duas capinas. Sendo assim, as plantas daninhas presentes na área experimental representaram aquelas que escaparam ao controle com os herbicidas. O herbicida mesotrione, recomendado para aplicação em pós-emergência, não possui ação em pré-emergência, ou seja, sobre o banco de sementes do solo. Já o herbicida atrazine, mesmo aplicado em pós-emergência, pode apresentar algum efeito de inibição na germinação de plantas daninhas sensíveis, presentes no solo. Herbicidas do grupo químico das triazinonas são usados para controle seletivo em pré e pós-emergência das plantas daninhas mono e dicotiledôneas na cultura do milho (Rizzardi et al., 2004). Sendo assim, mesmo aplicado em pós-emergência, pode ter ocorrido um pequeno efeito de herbicida pré-emergente se este tiver atingido o solo.

No híbrido 30P70 ocorreu redução de aproximadamente 35\% na fitomassa de plantas daninhas reinfestantes (Tabela 8). Isto ocorreu porque este híbrido apresenta características como, maior NFP e também uma maior AP, o que foi verificado tanto aos 0 DAA como aos 40 DAA, tais características do híbrido, provavelmente, permitiram melhores condições de luz para 0 desenvolvimento do milho e piores condições para o desenvolvimento das plantas daninhas. Entretanto, o híbrido 30K75 apresentou menor AP e menor NFP, favorecendo a entrada de luz na entrelinha da cultura do milho, propiciando maior penetração da luz devido ao maior espaço físico e, com isso, causando maior reinfestação de plantas daninhas. 
Vale lembrar, que antes da aplicação dos tratamentos foi feita uma aplicação em área total de inseticida, visando o controle da Spodoptera frugiperda, o que pode ter acarretado em redução da produtividade. De maneira semelhante, Cruz (2003) ressalta que no cultivo do milho a presença da Spodoptera frugiperda é prejudicial ao desenvolvimento da planta e pode gerar perdas na produção e na qualidade dos grãos de milho.

A produtividade de grãos de milho não diferiu significativamente em função das misturas de herbicidas e inseticidas testadas (Tabela 8). Quando dos tratamentos a base de mesotrione, os híbridos de milho produziram $6 \%$ e 1,4\% a mais de grãos, que quando dos tratamentos a base de atrazine e atrazine + mesotrione, respectivamente. As plantas pulverizadas com lufenuron produziram em média $3,2 \%$ a mais de grãos, do que aquelas tratadas com metomyl, independentemente do herbicida utilizado em mistura. A produtividade foi significativamente maior para o híbrido 30P70, que produziu uma média de $10.199 \mathrm{~kg} \mathrm{ha}^{-1}$, ou seja, aproximadamente $8 \%$ a mais que o híbrido 30K75. Os resultados corroboram com os de Bachiega e Soares (2002), uma vez que seus dados mostraram que os herbicidas e suas misturas com inseticidas não causaram efeitos negativos para os híbridos de milho por eles estudados, comprovando também, a existência de diferenças de potencial produtivo entre os híbridos.

A determinação da diferença entre potencial produtivo dos híbridos pode ser devido ao número de espigas por planta, tendo em vista que o número de grãos por espiga (produto entre número de fileiras por espiga e número de grãos por fileira) e principalmente a fitomassa de 1000 grãos não diferiram (Tabela 8).

Quanto à fitomassa de 1000 grãos de milho (FMMG), verificou-se a ocorrência de interação entre herbicidas e inseticidas para os dois híbridos avaliados. Quando o herbicida atrazine foi aplicado em mistura com o inseticida lufenuron, o resultado foi maior FMMG, para os híbridos testados. Já o herbicida atrazine, aplicado em mistura com o metomyl, resultou em menor FMMG, para os híbridos testados (Tabela 9).

TABELA 9. Desdobramento dos efeitos da interação entre herbicidas e inseticidas sobre a fitomassa de 1000 grãos de híbridos de milho. UEPG, Ponta Grossa-PR.

\begin{tabular}{c|ccc|ccc}
\hline & \multicolumn{1}{|c}{ FITOMASSA DE 1000 GRÃOS DE MILHO (G) } \\
\hline \multirow{2}{*}{ Tratamentos } & \multicolumn{5}{c}{ Inseticidas } \\
\cline { 2 - 7 } & \multicolumn{3}{c}{ Lufenuron } & \multicolumn{3}{c}{ Metomyl } \\
\hline Herbicidas & 328,8 & ab & A & 342,1 & a & A \\
Mesotrione (mes.) & 341,7 & a & A & 324,3 & a & B \\
Atrazine (atraz.) & 313,7 & b & A & 323,9 & a & A \\
mes. + atraz. & 313,7 &
\end{tabular}

Médias seguidas da mesma letra minúscula, comparadas na coluna, e letra maiúscula, comparadas na linha, não diferem statisticamente entre si pelo teste de Tukey $(P>0.05)$. 
É sabido que a reação dos híbridos de milho a herbicidas pós-emergentes difere quanto ao grau de seletividade (Nicolai et al., 2003), ou seja, há variações na absorção e translocação do herbicida entre híbridos de milho. Fato este confirmado por Oliveira Jr. (2001a), o qual afirma que a seletividade está associada à translocação diferencial. Mesmo que o aumento na população de plantas de milho não resulte em aumento na produção, este fator pode aumentar a competitividade da cultura sobre as plantas daninhas devido à maior quantidade de luz que é interceptada pelo dossel da cultura (Balbinot Jr. e Fleck, 2005).

\section{CONCLUSÕES}

A mistura de inseticidas com herbicidas causou efeito no número de folhas, diâmetro de colmo e fitomassa de 1000 grãos. No entanto, não existiram diferenças significativas para a mistura de inseticidas com herbicidas para os componentes da produção, com exceção para a fitomassa de 1000 grãos. Os inseticidas não afetam a seletividade dos herbicidas. O híbrido de milho 30P70 apresentou maior potencial produtivo para as condições do experimento, apresentando média de $10.199 \mathrm{~kg} \mathrm{ha}^{-1}$.

\section{REFERÊNCIAS BIBLIOGRÁFICAS}

ALVES, E., CORRÊA, M.R., CATANEO, A.C., VELINI, D., CAVARIANI, C. Avaliação da seletividade de cultivares de milho a mesotrione + atrazine e a metolachlor em função da atividade de glutationa S-transferase. Boletim Informativo SBCPD, São Paulo, v.10, Suplemento, p.132, 2003.

BACHIEGA, A.L., SOARES, J.E. Callisto (mesotrione) - Novo herbicida para o controle de plantas daninhas em pós-emergência, na cultura do milho. In: CONGRESSO BRASILEIRO DA CIENCIA DAS PLANTAS DANINHAS, 23., Londrina, 2002. Resumos. Londrina: SBCPD; Embrapa Clima Temperado, 2002. p.655.

BALBINOT JR., A.A., FLECK, N.G. Competitividade de dois genótipos de milho (Zea mays) com plantas daninhas sob diferentes espaçamentos entre fileiras. Planta Daninha, v.23, n.3, p.415-421, 2005.

CATANEO, A.C., VELINI, E.D., ALVES, E., FERREIRA, L.C. Identificação da susceptibilidade diferencial de híbridos de milho (Zea mays L.) a mistura dos herbicidas callisto e primóleo, através de determinações bioquímicas e fisiológicas. Boletim Informativo - Sociedade Brasileira da Ciência das Plantas Daninhas, Brasil, v.10, n. Suplemento, p.134-134, 2004. 
CHRISTOFFOLETI, P.J., MENDONÇA, C.G. Controle de plantas daninhas na cultura de milho: enfoque atual. In: FANCELLI, A.L.; DOURADO NETO, D. (Coord.) Milho: tecnologia e produtividade. Piracicaba: ESALQ/LPV, 2001. p.60-95.

COELHO, A.M., CRUZ, J.C., PEREIRA FILHO, I.A. Rendimento do milho no Brasil: chegamos ao máximo? Piracicaba: POTAFOS, (Informações Agronômicas, 101), p.1-12, 2003.

COMPANHIA NACIONAL DE ABASTECIMENTO. Comparativo da área, produtividade e produção safra 2016/2017 e 2017/2018. Disponível em 06/dez/2017: <http://www.conab.gov.br/>.

CRUZ, I. Manejo de pragas na cultura do milho. In: FANCELLI, A.L., DOURADO-NETO, D. (Eds.). Milho: estratégias de manejo para alta produtividade. Piracicaba/SP: ESALQ/USP/LPV, 2003. p.1946.

FANCELLI, A.L., DOURADO NETO, D. Produção de milho. Guaíba: Livraria e Editora Agropecuária, 2000. 360p.

FARIA, R.M., BARROS, R.E., TUFFI SANTOS, L.D. Weed interference on growth and yield of transgenic maize. Planta daninha, Viçosa, v.32, n.3, p.515-520, 2014.

GASSEN, D.N. O risco da mistura de herbicidas com inseticidas em milho. In: GASSEN, D.N. (Ed.) Informativos Técnicos Cooplantio. Passo Fundo: Aldeia Norte Editora, 2002. p.125-128.

JAKELAITIS, A., SILVA, A.A., FERREIRA, L.R., SILVA, A.F., PEREIRA, J.L., VIANA, R.G. Efeitos de herbicidas no consórcio de milho com Brachiaria brizantha. Planta Daninha, Campinas, v.23, n.1, p.69-78, 2005.

LÓPEZ-OVEJERO, R.F., CHRISTOFFOLETI, P.J., NICOLAI, M., BARELA, J.F. Manejo de plantas daninhas na cultura do milho. In: FANCELLI, A.L., DOURADO-NETO, D. (Ed.). Milho: estratégias de manejo para alta produtividade. Piracicaba:ESALQ, LPV, 2003a. p.47-79.

LÓPEZ-OVEJERO, R.F., FANCELLI, A.L., DOURADO-NETO, D., GARCÍA y GARCÍA, A., CHRISTOFFOLETI, P.J. Seletividade de herbicidas para a cultura de milho (Zea mays) aplicados em diferentes estádios fenológicos da cultura. Planta Daninha, Viçosa, v.21, n.3, p.413-419, 2003b.

MEROTTO JR., A., VIDAL, R.A., FLECK, N.G., REIS, B., ANDRES, A. Diminuição da competição de Brachiaria plantaginea em milho através de capinas e herbicidas empregados em diferentes épocas. Planta Daninha, v.18, p.471-477, 2000. 
NASSER, L.D. Resposta da cultura do milho (Zea mays) à mistura de herbicidas, inseticidas e adubo foliar nitrogenado. Trabalho OTCC - Universidade Estadual de Ponta Grossa, Ponta Grossa, 2006.

NICOLAI, M., OVEJERO, R.L., ABUJAMRA, C., BARELA, J.F., CHRISTOFFOLETI, P.J. Avaliação de Tolerância de Híbridos de Milho ao Herbicida Mesotrione. Boletim Informativo Ciência das Plantas Daninhas SBCPD, Piracicaba, v.10, n. Suplemento, p.130-130, 2003.

OLIVEIRA JÚNIOR, R.S. Mecanismo de ação de herbicidas. In. OLIVEIRA JUNIOR. R.S.; CONSTANTIN, J. (Coord.). Plantas daninhas e seu manejo. Guaíba:Agropecuária, 2001a. p.207260.

OLIVEIRA JÚNIOR, R.S. Seletividade de herbicidas para culturas e plantas daninhas. In. OLIVEIRA JÚNIOR, R.S.; CONSTANTIN, J. (Coords.). Plantas daninhas e seu manejo. Guaíba: Agropecuária, 2001b. p.291-314.

RAHMAN, A., JAMES, T.K. Enhanced activity of nicosulfuron in combination with soil applied insecticides in corn (Zea mays). Weed Technology, v. 7, p. 824-829, 1993.

RAMOS, L.R.M., PITELLI, R.A. Efeitos de diferentes períodos de controle da comunidade infestante sobre a produtividade da cultura do milho. Pesquisa Agropecuária Brasileira, v. 29, p.1523-1531, 1994.

RIZZARDI, M.A., VARGAS, L., ROMAN, E.S., KISSMAN, K. Aspectos Gerais do Manejo e Controle de Plantas Daninhas. In: Manual de Manejo e Controle de Plantas Daninhas. EMBRAPA, Bento Gonçalves. p.123. 2004.

ROSSI, I. H., OSUNA, J.A., ALVES, P.C.A., BEZUTTE, A.J. Interferência das plantas daninhas sobre algumas características agronômicas e a produtividade de sete cultivares de milho. Planta Daninha, Botucatu, v.14, 1996.

SILVA, F. de A.S.; AZEVEDO, C.A.V. de. Principal Components Analysis in the Software AssistatStatistical Attendance. In:WORLD CONGRESS ON COMPUTERS IN AGRICULTURE, 7, Reno-NVUSA: American Society of Agricultural and Biological Engineers, 2009.

SILVA, A.A., FREITAS, F.M., FERREIRA, L.R., JAKELAITIS, A. Efeitos de mistura de herbicidas com inseticidas sobre a cultura do milho, as plantas daninhas e a lagarta-do-cartucho. Planta Daninha, Viçosa, v.23, n.3, p.517-525, 2005a. 
SILVA, A.A., FREITAS, F.M., FERREIRA, L.R., JAKELAITIS, A., SILVA, A.F. Aplicações sequenciais e épocas de aplicação de herbicidas em mistura com chloropirifós no milho e em plantas daninhas. Planta Daninha, Viçosa, v.23, n.3, p.527-534, 2005b.

TAIZ, L., ZEIGER, E., MOLLER, I.M., MURPHY, A. Fisiologia e desenvolvimento vegetal. 6. ed. Porto Alegre: Artmed, 2017. 858p.

ZAGONEL, J., VENÂNCIO. W.S., KUNZ, R.P. Efeito de métodos e épocas de controle das plantas daninhas na cultura do milho. Planta Daninha, v.18, n.1, p.143-150, 2000. 